\title{
ANOTHER APPROACH TO BECKNER'S INEQUALITY
}

Abstract. A classical inequality which was proved by Beckner is an important tool for the study of Banach space geometry. In this note, we present another proof of that inequality.

Mathematics subject classification (2010): 46B20.

Keywords and phrases: Beckner's inequality.

\section{REFERENCES}

[1] W. BECKNER, Inequalities in Fourier analysis, Ann. of Math., 102 (1975), 159-182.

[2] K. Kuriyama, M. Miyagi, M. OKada And T. Miyoshi, Elementary proof of Clarkson's inequalities and their generalization, Memories of the Faculty of Engineering, Yamaguchi Univ., 48 (1997), $119-125$.

[3] J. Lindenstrauss And L. TZafriri, Classical Banach spaces II, Springer-Verlag, Berlin, 1979.

[4] K.-I. Mitani And K.-S. SAito, Dual of two dimensional Lorentz sequence spaces, Nonlinear Anal., 71 (2009), 5238-5247. 
[5] K.-I. Mitani, K.-S. Saito And T. Suzuki, On the calculation of the James constant of Lorentz sequence spaces, J. Math. Anal. Appl., 343 (2008), 310-314.

[6] H. Mizuguchi And K.-S. SAito, A note on Clarkson's inequality in the real case, J. Math. Inequal., 4 (2010), 129-132.

[7] Y. Yamada, Y. TAKAhashi And M. Kato, On Hanner type inequalities with a weight for Banach spaces, J. Math. Anal. Appl., 324 (2006), 1228-1241. 